\title{
Retina Görüntülerindeki Kan Damarlarının Belirlenmesi
}

\author{
Erkan TANYILDIZI ${ }^{*}$, Serhat OKUR ${ }^{1}$ \\ ${ }^{1}$ Fırat Üniversitesi, Teknoloji Fakültesi, Yazılım Mühendisliği, Elazığ. \\ *etanyildizi@firat.edu.tr
}

(Geliş/Received: 01.12.2015; Kabul/Accepted: 10.05.2016)

\begin{abstract}
Özet
İnsanlarda ortaya çıkan hastalıkların bazıları, gözdeki retina tabakasında bulunan kan damarlarının yapısının bozulmasına neden olmaktadır. $\mathrm{Bu}$ nedenle retinadaki kan damarlarının yapısal bozukluklarının önceden teşhisi bazı hastalıkların tedavisine olanak sağlamaktadır. Retinadaki kan damarlarının çıkarılması için çeşitli yöntemler bulunmaktadır. Bu çalışmada damar çıarma için kullanılan yöntemlerden bahsedilmiş ve görüntü işleme kütüphanesi OpenCV kullanılarak gözdeki retina tabakasında bulunan kan damarlarının çıkarılması uygulaması açıklanmıştır.
\end{abstract}

Anahtar Kelimeler: Görüntü İşleme, Kenar Çıkarma ve Sınırlar, Şekil İşleme, Nesne Belirleme

\section{Extracting Blood Vessels In Retina Layer Images}

\begin{abstract}
Some of the diseases that occur in people cavses the deterioration of blood vessesls in the retina layer structure. For that reason, diagnosing the deterioration of blood vessels in retina layer structrure makes it possible to treat various diseases. There are several methods used to extract blood vessels in retina in this study the methods extracting blood vessels are mentioned and the implementation of extracting blood vessels in retina layer using OpenCV which is an image processing library is explained.
\end{abstract}

Keywords: Image Processing, Edge Detection and Contours, Shape Processing, Object Recognition

\section{Giriș}

Gelişen teknoloji ve karmaşıklaşan dünyada insanlar artık hastalığa sebep olan daha fazla tehditle karşı karşıyadır. Bu tehditlerden ötürü insanlarda birçok hastalık kendini göstermektedir. İnsanlarda ortaya çıkan hastalıklardan bir bölümü, gözdeki retina tabakasinda bulunan morfolojik yapıların bozulmasına neden olmaktadır. Bu nedenle retinal görüntülerdeki kan damarları, optik disk ve makula gibi morfolojik yapıların ve oluşan dejenerasyonların otomatik olarak tespiti, retinal görüntülerden hastalık tespit ve takibinde son derece önemlidir [1-6]. Retina görüntülerinden kan damarlarının otomatik olarak çıarılması diyabetik retinopati, glakom, damar sertliği, retinal alter tıkanıklığı vb. hastalıkların bilgisayar destekli tanı ve tedavisinde önemli bir adımdır[7]. Bu yüzden bu alanda otomatik olarak bu fonksiyonları gerçekleştiren sistemlere büyük ihtiyaç vardır. Otomatik sistemlerin geliştirilip kullanılması çok büyük veri yığınlarını görsel olarak inceleyip analiz eden sağlık personelinin iş yükünü de önemli ölçüde azaltacaktır[8]. $\mathrm{Bu}$ konuda insanların ihtiyaçlarını karşılayan, yaşamını kolaylaştıran çalışmalardan bazıları Görüntü İşleme (Image Processing) konularıdır[9].

Görüntü işleme algılanan görüntüden yeni bir görüntü elde edilmesi için yapılan işlemlerdir[10]. Görüntü işlemeyi kullanım amaçları, görüntüyü iyileştirme, onarma, sıkıştırma, analiz etme ve tanıma gibi amaçlardır[11]. Görüntü işlemenin uygulama alanları oldukça geniş olup, kullanıldığı alanlarda insanlığa sağladığı yararlar oldukça fazladır. Görüntü işleme: tıp (hastalık/kırık belirleme, nodül tespiti, damar belirleme, nesne sayma ve MR, ultrason, gama 1şını, tomografi görüntülerinin iyileştirilmesi), uzay çalışmaları (gezegenler, uydular, gökyüzü olayları), uzak yeryüzü kaynaklanı araştırmalanı (uydu görüntüleri), güvenlik (yüz/parmak izi tanıma, hareket tespiti), mühendislik (kalite kontrol), film efektleri, yayıncıllk, spor, sanat, belgelerin sayısallaştırılması (Optical Cahracter Recognition/Optik Karakter Tanıma (OCR), kütüphaneler), askeri uygulamalar (hedef tespiti, insansız hava araçları, gece görüşü) gibi birçok alanda kullanılabilmektedir[12]. Görüntü işleme teknikleri ile yapılan çalışmalar bilgisayar bilimlerinin insanoğlunun hayatını ne derece kolaylaştırdığını ortaya koymaktadır. 
Bir görüntünün kullanışlı bir şekilde işleme tabi tutulabilmesi için öncelikle bu görüntünün bilgisayar tarafindan anlaşılabilecek hale dönüștürülmesi gerekmektedir. $\mathrm{Bu}$ dönüşüm işlemine görüntünün sayısallaştırılması denir[10].

Görüntü sayısallaştırıldıktan sonra çeşitli algoritmalar kullanılarak görüntünün istenilen hale gelmesi sağlanabilir. Bu algoritmaları uygulamak için çeşitli yazılım dilleri ve kütüphaneler mevcuttur. OpenCV, SimpleCV, Aforge.NET, OpenGL, gibi görüntü işleme alanında kullanılan bazı genel kullanıma açık kütüphane ve araçlardır[11].

Retina görüntülerinden kan damarlarının ayrıştırlarak hastalık teşhisinin daha kolay yapılmasını sağlamaktır. Özellikle "Diyabetik Retinopati” hastalığının teşhisinde retina görüntüsünden kan damarlarının belirlenmesi oldukça önem arz etmektedir. Çünkü diyabetik retinopati sebebiyle retinadaki kan damarlarını yapısı bozularak küçük baloncuklar meydana gelir, kanamalara ve damar içindeki sıvının etraf dokulara sizmasina neden olur. İlerleyen evrelerde ise retina üzerinde istenmeyen yeni damar tomurcukları oluşur ve ani göz içi kanamaya sebep olur. Literatürde retina görüntülerinden kan damarlarının ayrıştırılması için çeşitli çalışmalar yapılmıştır.

Damarların çıkarılması için kullanılan algoritmalar genel olarak iki grupta incelenmektedir[13]. Birinci grup algoritmalar kural tabanlı olarak isimlendirilmekte ve Damar İzleme $[14,15]$, Uyum Süzgeç Tepkisi $[16,17]$ ve Morfoloji Tabanlı yöntemleri [18-20] kapsamaktadır. İkinci gruptaki algoritmalar ise danışmanlı algoritmalardır ve genellikle piksel sinıflandırması sinir ağı modelleri ve özel tasarlanmış sınıflandırıcılar kullanırlar [21]. Piksel sınıflandırması için KNN (k En Yakın Komşuluk) [21], Bayesgil Karar [22], Destek Vektör Makineleri [23], YSA [24] gibi sinıflandirıcilar kullanılmaktadır.

Damar çıkarma konusunda yapılan çalışmalardan bir tanesi Chaudhuri ve arkadaşları tarafindan yapılmış ve bu çalışmada damar çıkarma uygulaması için uyum süzgeci (Matched Filter) önermişlerdir[16].

Hoover ve arkadaşlan 2000 yılında yaptıkları çalışmalarında retinal kan damarlarının çıkarılması için çalşsmasında önerilen iki boyutlu uyum süzgecinin uygulanmasından sonra uygun eşik değerini bulmak için "threshold probing" yöntemi önermişlerdir[17].
Martinez-Perez ve arkadaşları 2007 yılında yaptıkları çalışmada retina üzerinde bulunan damarların farklı genişliklerde olması nedeniyle çok ölçekli özellik çıkarmaya dayalı bir yöntem önermişlerdir. Hessian matris ve yön büyüklük değerlerinin yerel maksimum değerleri kullanılarak retinal kan damarları belirginleştirilmiş, daha sonra da özel bir bölge büyütme yöntemi ile damarlar çıkarmışlarıdır[18].

Soares J.V.B. ve arkadaşları 2006 yılındaki çalışmalarında piksel parlaklık değerleri üzerinde faklı ölçeklerde Gabor-Dalgacık dönüşümü uygulamıştır. Daha sonra elde edilen farklı ölçekteki Gabor-Dalgacık dönüşüm çıttıları özellik olarak kullanılarak tüm görüntü Bayesgil Sinıflandırıc1 uygulanarak damar ya da damar olmayan bölgelere ayrilmıştır[22].

Ricci ve arkadaşlanı damar çıkarma işlemi için daha önce mamografi görüntüleri için kullanılan çizgi operatörünü kullanmışlar ve bu operatörün görüntü çıktısını Destek Vektör Makineleri kullanan sınıflandırıcıya giriş olarak vermişlerdir[23].

Marin ve arkadaşları 2011 yllındaki çalışmalarında retinal görüntülerdeki piksellerin gri seviye özellikleri ile moment değişmezleri tabanlı özellikler kullanarak sinir ağı tasarlamışlardır[24].

Jiang ve Mojon çalışmalarında adaptif yerel eşiklemeye dayalı bir yöntem önermişlerdir. $\mathrm{Bu}$ yönteme göre belli eşik aralıklarına göre tüm görüntü her bir eşik aralığına göre siyah beyaz görüntüye çevrilmiş ve elde edilen sonuç doğrulama prosedürü ile damar olabilecek yapılar seçilmiştir. Daha sonra ayrı ayrı eşik değerlerinden elde edilen damar yapıları birleştirilerek damar görüntüsü elde edilmiştir[25].

$\mathrm{Bu}$ çalışmanda retinadaki kan damarlarının belirlenmesi uygulamasını gerçekleştirilirken OpenCV görüntü işleme kütüphanesi kullanılmıştır. Çalışmada hastalık teşhisinin önemini anlayabilmek için tıbbi olarak göz ve gözdeki damarlarda deformeye neden olan Diyabetik Retinopati hastalığı hakkında bilgi verilmiş ve görüntü işlemede uygun yöntemler kullanılarak gözde bulunan retinadaki kan damarlarının çıarılması uygulaması gerçekleştirilmiştir.

\section{Göz ve Gözün Yapısı}

Göz, görme duyu organımızdır. İnsan gözü çok uzak mesafelerdeki nesneleri görebilme ve nesneleri sayısız renk ve şekil bilgisine göre ayırt edebilme yeteneğine sahiptir. 
Göz, koruyucu yapılar ve görme yapıları olarak iki kısımdan oluşmaktadır. Gözümüzde bulunan ve gözü koruyan yapılar incelendiğinde kirpikler, göz kapakları, göz kaslanı ve gözyaşı beşlerinden oluşmaktadır[26, 27].

1. Sert tabaka

2. Damar tabaka

3. Ağ tabaka (retina)

olmak üzere üç tabakadan oluşmaktadır.

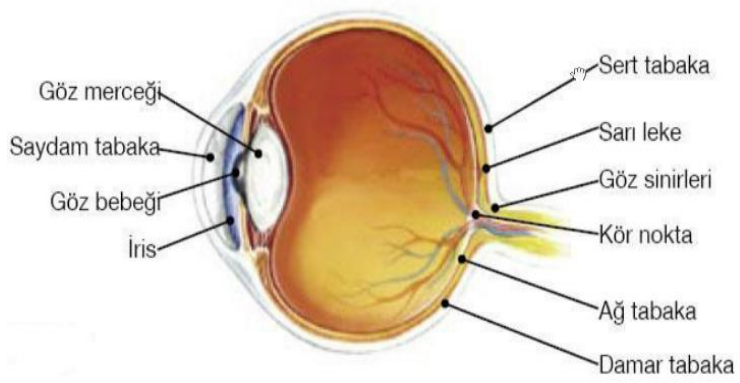

Şekil 1. Göz ve gözün yapısı

\subsection{Diyabetik retinopati}

Yüksek kan şekeri nedeniyle gözün retina tabakasındaki damarların hasar görmesi sonucunda ortaya çıkan bir hastalıktır[28]. Görmek için ıșığın hiçbir engel ile karșılaşmadan retinaya ulaşabilmesi gerekir. Diyabetik Retinopati hastalığ ile retinadaki kan damarları tıkanır, sızdırır veya rasgele büyür. $\mathrm{Bu}$ sonuçlar ise ışı̆ıı retinaya ulaşmasının önünde bir engel olmaktadır ve tedavi edilmediği takdirde görme yetisinin kaybolmasına kadar kötü sonuçlara varılabilir.

Diyabetik Retinopati proliferatif ve nonproliferatif olarak iki şekilde gerçekleşir. Hastalığın başlangıç esnasında nonproliferatif evre görünür. Bu evre bozuk damarlardan sıvı sızması ve retinada kanamalara sebep olur. Hastaların görme yetisi bu evrede genel olarak etkilenmez. Bu nedenle diyabeti olan her hastanın, görme yetisini kaybetmeden yılda bir kez göz muayenesi yaptırması gerekmektedir.

Tehlikeli olan evre ise proliteratif evredir. $\mathrm{Bu}$ evrede retina tabakasında ki damarların ileri derecede bozulmasına bağlı beslenemeyen bölgeler oluşur ve böylece yeni damarlar gelişir. Gelişen bu damarlar çok ince ve kırılgandır. Kendiliğinden göz içerisinde kanama yapabilir[29].

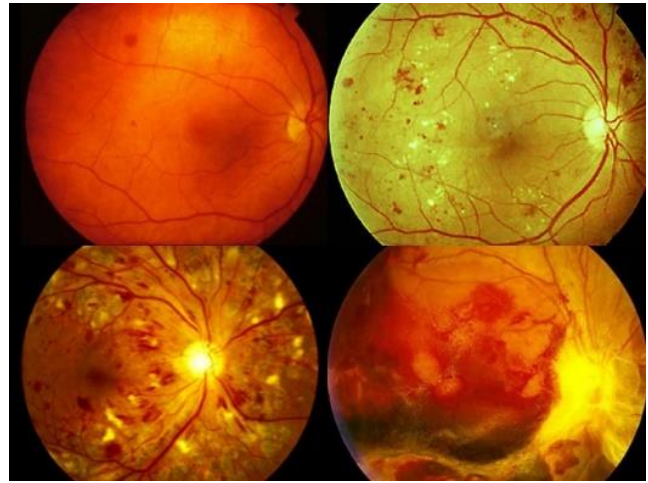

Şekil 2. Diyabetik retinopati evreleri: Hafif nonproliferatif diyabetik retinopati (sol üst), orta derece non-proliferatif diyabetik retinopati (sağ üst), şiddeti non-proliferatif diyabetik retinopati (sol alt), proliferatif diyabetik retinopati (sağ alt).

\section{Retina Görüntüsünden Damar Çıkarma Uygulaması}

Retina görüntülerinden damarların çıkarılması için daha önce yapılmış çalışmalarda Kirsch Operatör, Matched Filter gibi bazı yöntemler kullanılmıştır.

Kirsch operatörü, kenarları algılamak için 8 tane kernel matrisi kullanmaktadır[30,31]. Bu nedenle Șekil 3' deki 3x3 lük bir kernel matrisi 45 derecelik açılarla döndürülerek 8 tane kernel matrisi elde edilip bu kernel matrisleri kullanarak kenarları algilamaktadır.

\begin{tabular}{|c|c|c|}
\hline+5 & +5 & +5 \\
\hline-3 & 0 & -3 \\
\hline-3 & -3 & -3 \\
\hline
\end{tabular}

Şekil 3. 3x3' lük kernel matrisi

Her pikselin komşusuna bu elde edilen sekiz kernel matrisi sirasıyla uygulanır ve sonuçta her piksel sekiz çıkışa sahip olur[32]. Bu sekiz çıkıştan maksimum değere sahip olan seçilir[33]. Bu işlemi gerçekleștirebilmek için elde edilen kernel matrisler Denklem 1' de verilen eşitlik yardımıyla resim üzerine uygulanarak retina görüntüsü üzerindeki kenarlar algilanıp damarlar tespit edilmektedir.

$h_{n m}=\max _{Z=1 \ldots . .8} \sum_{i=-1}^{1} \sum_{j=-1}^{1} g_{i j}^{(z)} \cdot f_{n+i, m+j}$ 
Matched Filter, retina görüntülerinde kan damarlarının tespiti için önerilmiştir[16]. Bir önbilgi kullanarak damarların kesiti Gauss fonksiyonu ile tahmin edilebilir. Bu nedenle gauss şekliyle eşleşen damarların tespiti için bir filtre kullanılabilir[34].

$$
\begin{aligned}
& f(x, y)=\frac{1}{\sqrt{2 \pi} s} \exp \left(-\frac{x^{2}}{2 s^{2}}\right)-m, \\
& |x| \leq t . s \text { ve }|y| \leq \frac{L}{2}, i c ̧ i n
\end{aligned}
$$

Matched Filter olarak tanımlanan Denklem 2'de $x$ ve $y$ görüntünün satır ve sütunlarını, $s$ ise filtre ölçeğini temsil eder, ortalama değeri $O$ olan Denklem 2' deki filtreyi normalize etmek için Denklem 3 kullanılır. Böylece pürüzsüz arka plan kaldırlarak damarlar çıkarlabilmektedir.

$$
m=\left(\int_{-t s}^{t s} \frac{1}{\sqrt{2 \pi} s} \exp \left(-\frac{x^{2}}{2 s^{2}}\right) d x\right) /(2 t s)
$$

$\mathrm{Bu}$ yöntemlerin en büyük sorunu sadece damarları değil damar olmayan kenarları da çıarmasıdır. Yapılan çalışmalarda bu yöntemlerin kodları MATLAB ortamında gerçekleştirilmiştir.

Uygulamalarda hız önemlidir, bunun için makine diline en yakın üst düzey programlama dilleri tercih edilmelidir[35]. Bu nedenle bu çalışmada kullanılan yazılım geliştirilirken Intel şirketinin görsel bilgisayar uygulamaları için geliştirdiği OpenCV Kütüphanesi kullanılmıştır. $\mathrm{C}$ ve $\mathrm{C}++$ arayüzüne sahip bir kütüphane olan OpenCV' nin MATLAB' a göre en büyük avantajı açık kaynak kodlu bir kütüphane olmasıdır.

Çalışması kapsamında geliştirilen uygulamada kontör bulma, kontör alanı belirleme ve kontör çizme fonksiyonları kullanılarak retina görüntüsündeki damarların belirlenmesi işlemi gerçekleştirilmiştir.

Retina görüntüsündeki damarların belirlenmesi için bu uygulamada Şekil 4' deki yol takip edilmiştir.

\subsection{Retina görüntüsüne ön işlem}

Retinadaki kan damarlarının tespiti için fundus kamerayla çekilmiş retina görüntüsünün gri seviyeye indirgenmesiyle başlamaktadır. Gri seviyeye indirgenmiş retinal fundus görüntülerde yer alan kan damarlarını arkaplana göre daha da belirginleştirmek ve kümeleme işleminde ayırt edilmesini kolaylaştırmak için görüntünün bazı aşamalardan geçmesi gerekmektedir[13]. Bu aşamalar;
1. Filtreleme işlemi

2. Eşikleme işlemi

olarak kullanılmaktadır. Bu uygulamada filtreleme işlemi için median ve gauss filtreleri, eşikleme işlemi için ise adaptif eşikleme yöntemleri kullanılmıştır.

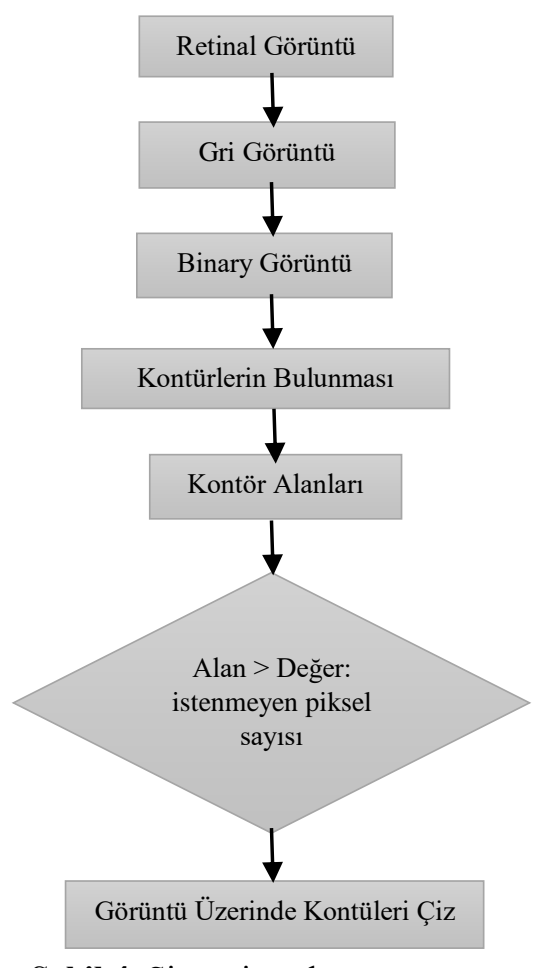

Şekil 4. Sistemin çalışma şeması

\subsubsection{Median (Ortanca) filtreleme}

Median filtre genellikle salt \& pepper denilen bozulma türünü gidermek için kullanılmaktadır.

\begin{tabular}{|c|c|c|}
\hline 4 & 5 & 6 \\
\hline 1 & 7 & 8 \\
\hline 3 & 2 & 9 \\
\hline
\end{tabular}

Şekil 5. 3x3' lük örnek kernel matrisi

Şekil 5' deki verilen $3 \times 3$ lük bir kernel matrise median filtre uygulandığında filtre, matris elemanlarını büyükten küçüğe doğru sıralayacak ve ortanca elemanı matrisin ortasına yani $(2,2)$ numaralı indise yerleştirecektir. 


\begin{tabular}{|c|c|c|c|}
\hline 1 & 2 & 3 \\
\hline 4 & 5 & 6 \\
\hline 7 & 8 & 9 \\
\hline Şekil 6. 3x3' lük Örnek Kernel Matrisi Median Filtre \\
Uygulandıktan Sonra
\end{tabular}

\subsubsection{Gauss filtreleme}

Median filtrenin Gaussian dağılımını kullanarak biraz daha değiştirilmiş hali Gaussian filtresi olarak bilinir. Gaussian filtreleme aynı zamanda bir fourier dönüşümüdür. Gauss filtre ile sonsuz bir transfer fonksiyonuna karşılık mekânsal alanda sonlu bir pencerede (tarama penceresi) filtreleme yapilabilmektedir. $\mathrm{Bu}$ da filtrelemenin temel problemini daha kolay çözülebilir hale getirir. Gauss filtresi uygulandığ resme belirtilecek maske boyutunda bir matris ile tarama işlemi yapmakta ve her bir matriste ağırlıklı ortalamayı hesaplamaktadır.

Gauss yumuşatmasının avantajları, filtreleme önce yatay ardından çıkan sonuçla düşey eksende gerçekleştirilebilir.

$$
G(x, y)=\frac{1}{2 \pi \sigma^{2}} e^{-\frac{x^{2}+y^{2}}{2 \sigma^{2}}}
$$

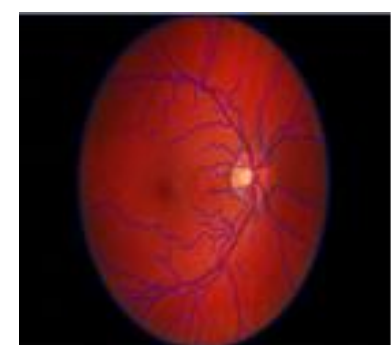

(a)

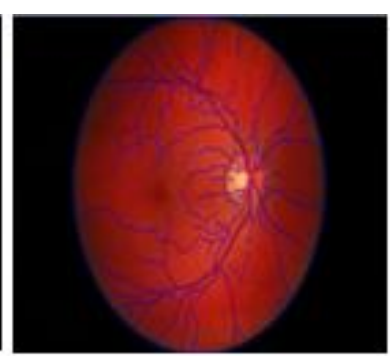

(b)
Şekil 7. (a) Median filtre uygulanarak damarları bulunan retina görüntüsü, (b) Gauss filtre uygulanarak damarları bulunmuş retina görüntüsü

\subsubsection{Eşikleme işlemi}

Eşikleme (thresholding) genellikle resmi binary resme (ikili yani siyah / beyaz resim) çevirmek için kullanılan bir tekniktir. Gürültüyü önlemek veya nesne belirlemek gibi farklı amaçlarla da kullanılabilmektedir. Genel olarak belirlenen bir sinır değeriyle resmin tüm piksellerinin teker teker karşılaştırılması ve belirli bir kurala göre resmi 0 (sıfir) ve 1 (bir)' e dönüştürme uygulamasıdır.

$$
\begin{array}{ll}
G(i, j)=1 & f(i, j) T i c ̧ i n \\
G(i, j)=0 & f(i, j)<T i c ̧ i n
\end{array}
$$

olarak verilmektedir. Burada:

$$
\begin{aligned}
& T \quad \rightarrow \text { Essik değeri } \\
& G(i, j)=1 \rightarrow \text { Objenin görüntü elemanları } \\
& G(i, j)=0 \rightarrow \text { Objenin görüntü elemanlarıdır } .
\end{aligned}
$$

Doğru bir eşik değeri seçimi başarılı bir sonuç için çok önemlidir.

\subsection{Retina görüntüsünde damarların belirlenmesi}

Görüntü üzerinde gerekli ön işlemler yapıldıktan sonra şekil hatlarının belirlenmesi yöntemiyle retina görüntüsündeki damarların tespiti yapılabilmektedir.

Şekil hatlarının belirlenmesi yöntemiyle damarların tespit edilebilmesi üç aşamada gerçekleşmektedir.

İlk aşama olarak görüntü üzerindeki kontürlerin bulunması gerekmektedir. Kontürler (contours), basitçe aynı renk ve şiddete sahip bir sınır boyunca sürekli noktaları birleştiren bir eğri olarak tanımlanmaktadırlar. Şekil 8 'de bir retina görüntüsü üzerinde kontür bulma işlemi gerçekleştirilmiştir.

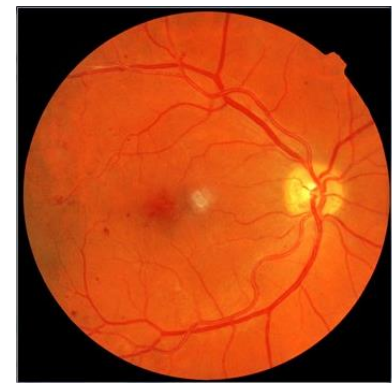

(a)

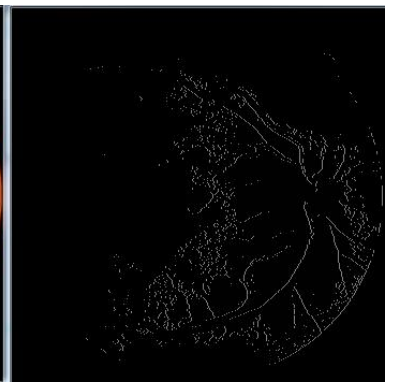

(b)
Şekil 8. (a) Orjinal retina görüntüsü, (b) Kontürleri bulunmuş retina görüntüsü

İkinci aşama olarak da bulunan kontürlerin alanı hesaplanmaktadır. Kontür alanlarını hesaplamadaki amaç kontür alanları belirlenirken bir sınır boyunca damar olmayan küçük parçalarda bulunmaktadır, bu nedenle küçük olan ve damar olmayan bu alanların istenmeyen bölge olarak belirlemek gerekmektedir. İstenmeyen alanlar belirlenirken girilen piksel sayısından daha küçük bir alana sahip kontürler üçüncü aşama ile işleme tabi tutulmamaktadırlar.

Üçüncü ve son aşamada ise kontürler bulunup istenmeyen alanlar yani belirli bir piksel sayısı altında 
kalan alanlar devre dışı bırakıldıktan sonra bu aşamada görüntü üzerinde tespit edilen kontürlerin üzeri çizilmekte ve belirgin bir hale getirilmektedir. Böylelikle orijinal retinal görüntüsü üzerindeki kan damarları belirgin bir hale getirilmiş olmaktadır.

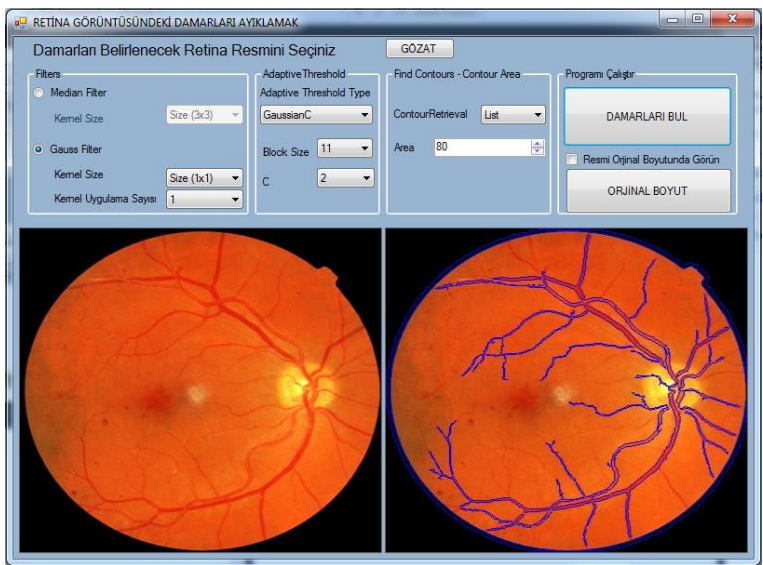

Şekil 9. Yapılan uygulamanın ekran görüntüsü

Şekil 9'da uygulama için tasarlanan form sayesinde retina görüntüsü üzerine uygulanacak filtreler, kernel matris boyutları, kontür belirleme yöntemleri, farklı eşik değerleri gibi seçenekler belirlenebilmekte ve değişiklikler görüntü üzerinde ananında görülebilmektedir. Böylelikle daha net görüntü elde edebilmek için çok fazla sayıda alternatif sunulmaktadır. Aynı zamanda uygulamalarda hiz önemli olduğu için uygulama geliştirilirken makine diline en yakın üst düzey programlama dilleri tercih edilmiş̧ir[35]. $\mathrm{Bu}$ nedenle çalışma kapsamında yapılan uygulamada şekil hatlarını belirleme fonksiyonları, etkin bellek kullanımı için OpenCV kütüphanesi aracı ile sağlanmıştır. $\mathrm{C}$ ve $\mathrm{C}++$ arayüzüne sahip bir kütüphane olan OpenCV' nin MATLAB' a göre en büyük avantajı açık kaynak kodlu ve tamamen ücretsiz bir kütüphane olmasıdır. Görüntü hızı konusunda OpenCV Matlab'a göre çok daha hızlıdır. Bunun nedeni bilgisayarımızda bir Matlab programı çalıştırıldığında bilgisayar bütün Matlab kodlarını yorumlamaktadır. OpenCV ise kısa zamanda kodu bilgisayara gönderir. Çok sayıda algoritmaya sahip olduğu için ekstra yorumlanmaya ihtiyacı yoktur. Bu yüzden Matlab'da yazılmış aynı programa göre çok daha hızlı çalışır. Anlık görüntü alma hızı çok daha fazladır. Eğer insanların gülümsemesini yakalayacak bir video görüntüsü için küçük bir program yazılacak olursa Matlab' da saniye de 3-4 fps yakalayabilirken, OpenCV' de 25-30 fps yakalanabilmektedir. Yine hızla yakından alakalı olarak, Matlab' da yazılan kodla görüntü işleme uygulaması gerçekleştirirken bilgisayar OpenCV 'ye oranla daha fazla bellek kullanımına ihtiyaç duymaktadır. Farklı retina görüntülerindeki damarların bu çalışma için gerçekleştirilen uygulamayla tespiti Şekil 10’ de gösterilmektedir.

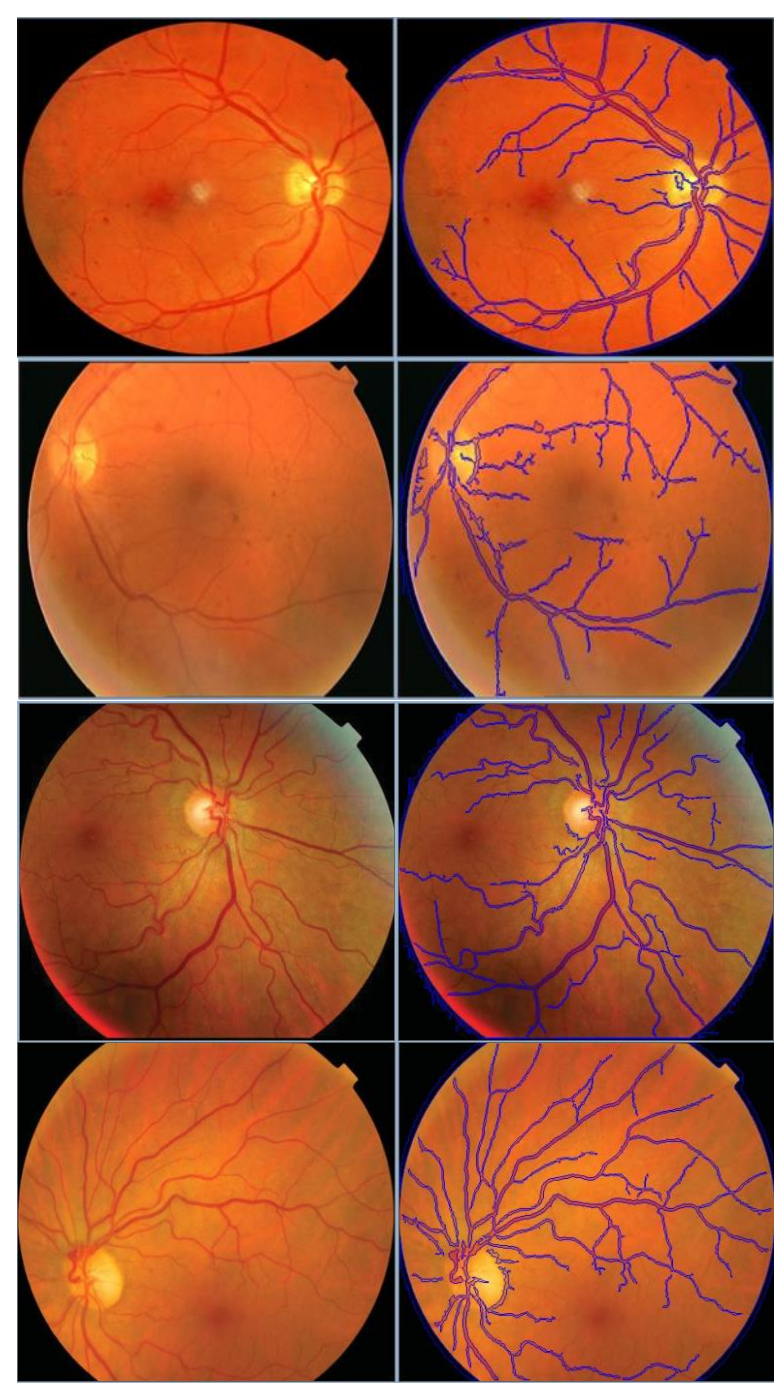

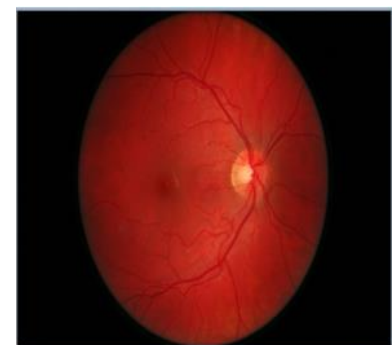

(a)

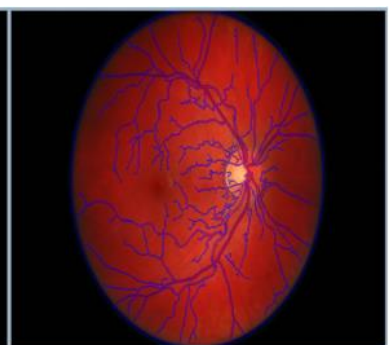

(b)
Şekil 10. Farklı retina görüntülerinin damarlarının tespiti (a) Orijinal retina görüntüsü, (b) Damarları belirlenmiş retina görüntüsü 
Uygun değerlerin girilmesi ve uygun filtreleme türünün seçimiyle retina görüntüsü üzerindeki damarların daha net ve belirgin bir șekilde çıkarılması gerçekleştirilebilmektedir. Uygulama için kullanılan görüntüler fundus kamerayla çekilmiş olup uygulama için önerilen sistem adımları izlenerek damarların belirlenmesi işlemi gerçekleştirilmiştir.

\section{Sonuç}

İnsan hayatının son yıllarda uzamasının en önemli nedenlerinden bir tanesi hastalıkların tespiti ve erken teşhisi için tıpta bilgisayar bilimleri ve görüntü işleme tekniklerinin kullanılmasıdır. Röntgen ve tomografi başta olmak üzere görüntü işleme tekniklerinin tıpta kullanılmasıyla bir çok hastalığa daha kolay ve erken teşhis konulabilmektedir.

İnsanlarda ortaya çıkan hastalıklardan bazıları retinada bulunan kan damarlarının yapisinda bozulmalara (kan damarlarının genişlemesi vb.) neden olmaktadır. $\mathrm{Bu}$ nedenle retinada bulunan kan damarlarındaki yapısal bozuklukların önceden teşhisi diyabetik retinopati, glakom, damar sertliği, retinal alter tıkanıklı̆g gibi bazı hastalıkların tedavisinde önemli rol oynamaktadır.

Retinada bulunan kan damarlarının yapısal bozukluklarının daha kolay teşhis edilebilmesi için retinadaki kan damarlarının retina görüntüsünden ayrıștırılması gerekmektedir. Retina görüntüsünden kan damarlarının ayrıştırılması için bilgisayar bilimleri ve görüntü işleme teknikleri kullanılmaktadır.

Çalışma kapsamında yapılan uygulamada şekil hatların belirleme fonksiyonlan, etkin bellek kullanımı için OpenCV kütüphanesi aracı ile sağlanmıştır. $\mathrm{C}$ ve $\mathrm{C}++$ arayüzüne sahip bir kütüphane olan OpenCV' nin MATLAB' a göre en büyük avantajı açık kaynak kodlu ve tamamen ücretsiz bir kütüphane olmasıdır. Görüntü hızı konusunda OpenCV Matlab'a göre çok daha hızlıdır. Matlab'da yazılan kodla görüntü işleme uygulaması gerçekleştirirken bilgisayar OpenCV 'ye oranla daha fazla bellek kullanmaktadır.

Uygulama için tasarlanan form sayesinde daha kolay bir kullanım sunulmakta ve bu form sayesinde girdi görüntüsü üzerinde yapılan değişikler çıktı görüntüsü üzerinde anında görüntülenebilmektedir. Bununla birlikte uygulama geliştirilirken OpenCV kullanılması sayesinde uygulamanın istenilen platformda herhangi bir programa ihtiyaç duyulmadan çalıştırılmasını sağlamaktadır.
Yapılan uygulamada OpenCV kütüphanesinde bulunan filtreleme yöntemleri ve şsekil bulma fonksiyonları ile retina görüntüsündeki kan damarlarının sınırları belirlenmiştir.

Bilgisayar sistemlerinin gelişmesiyle birlikte kullanılan bu yöntemler daha da gelişecektir. Böylece daha net ve hızlı sonuçlar elde edilebilecektir.

\section{Kaynaklar}

1. C. Sinthanayothin, J. F. Boyce, H. L. Cook, T. H. Williamson, Automated Location of the Optic Disc, Fovea, and Retinal Blood Vessels from Digital Colour Fundus Images, British Journal of Ophthalmology, Vol. 83(8):902-910, 1999.

2. J. Lowell, A.Hunter, D. Steel, A. Basu, R.Ryder, E. Fletcher, L. Kennedy, Optic Nerve Head Segmentation, IEEE Transaction on Medical Imaging, , Vol. 23, No. 2:2556-264, 2004.

3. L. Gagnon, M. Lalonde, M. Beaulieu, M.-C. Boucher, Procedure to detect anatomical structures in optical fundus images, Proceedings of Conference Medical Imaging 2001: Image Processing, pp. 12181225,2001

4. T. Teng, M. Lefley, and D. Claremont, "Progress towards automated diabetic ocular screening: A review of image analysis and intelligent systems for diabetic retinopathy," Med. Biol. Eng. Comput., vol. 40:2-13, 2002.

5. Köse C., Şevik U., Gençalioğlu O., Automatic segmentation of age-related macular degeneration in retinal fundus images, Computers in Biology and Medicine. Vol.: 38:611-619, 2008.

6. Köse C., Şevik U., Gençalioğlu O., İkibaş C., Kayıkçıŏlu T., A Statistical Segmentation Method for Measuring Age-Related Macular Degeneration in Retinal Fundus Images, Journal of Medical Systems, 2008, doi: 10.1007/s10916-008-9210-4.

7. Bob Z., Lin Z., Lei Z., Fakhri k., "Retinal Vesel Extrection By Matched Filter With First - Order Derivate Of Gaussian", Computers in Biology and Medicine, Vol. 40: 438-445, Issue 4, April 2010,

8. Yavuz Z., İkibaş C., Şevik U., Köse C., "Retinal Görüntülerde Optik Diskin Otomatik Olarak Çıkarılması İçin Bir Yöntem A Method For Automatic Optıc Disc Extraction In Retınal Fundus Images", Karadeniz Teknik Üniversitesi, Uluslararası İleri Teknolojiler Sempozyumu, Karabük 2009.

9. Kutlu H., "İnsan Bilgisayar Etkileşimli Görüntü İşleme Uygulamaları", Yüksek Lisans Tezi, T.C. Fırat Üniversitesi Fen Bilimleri Enstitüsü Elektronik ve Bilgisayar Eğitimi Anabilim Dalı Bilgisayar Sistemleri Eğitimi, Elazığ 2013. 
10. TÜRKOĞLU İ., "T.C. Firat Üniversitesi Fen Bilimleri Enstitüsü Elektronik ve Bilgisayar Eğitimi Anabilim Dalı Örüntü Tanıma Ders Notları”, Elazığ, 2010.

11. Ateş E., "Özgür Yazılımlarla Görüntü İşleme", Akademik Bilişim 2013, Antalya

12. Uğur A., "Görüntü İșlemeye Giriş", 2013.

13. Yavuz Z., Köse C., "Bulanık C-Kümeleme Algoritması ile Retinal Kan Damarı Bölütleme Retinal Vessel Segmentation with Fuzzy C-Means Clustering Algorithms" Bilgisayar Mühendisliği Bölümü Karadeniz Teknik Üniversitesi, Bursa 2012

14. Y. A. Tolias and S. M. Panas, "A fuzzy vessel tracking algorithm for retinal images based on fuzzy clustering", IEEE Trans. Med. Imag., vol. 17:263273, 1998

15. A. Can, H. Shen, J. N. Turner, H. L. Tanenbaum, and B. Roysam, "Rapid automated tracing and feature extraction from retinal fundus images using direct exploratory algorithms", IEEE Trans. Inform. Technol. Biomed., vol. 3: 125-138, 1999.

16. S. Chaudhuri, S. Chatterjee, N. Katz, M. Nelson, and M. Goldbaum, "Detection of blood vessels in retinal images using two-dimensional matched filters," IEEE Trans. Med. Imaging, pp. 263-269, 1989.

17. A. Hoover, V. Kouznetsova, and M. Goldbaum, "Locating blood vessels in retinal images by piecewise threshold probing of a matched filter response", IEEE Trans. Med. Imag., vol. 19:203-210, 2000.

18. M. E. Martínez-Pérez, A. D. Hughes, A. V. Stanton, S. A. Thom, A. A. Bharath, and K. H. Parker, "Scale-space analysis for the characterization of retinal blood vessels", Medical Image Computing and Computer-Assisted Intervention-MICCAI'99, 1999, pp. 90-97.

19. T. Walter and J. C. Klein, "Segmentation of color fundus images of the human retina: Detection of the optic disc and the vascular tree using morphological techniques", Medical Data Analysis, pp. 282-287, 2001.

20. F. Zana and J. C. Klein, "Segmentation of vessel-like patterns using mathematical morphology and curvature evaluation", IEEE Trans. Image Processing, vol. 10, no. 7, pp. 1010-1019, 2001.

21. J. Staal, M. D. Abrmoff, M. Niemeijer, M. A. Viergever, and B. V. Ginneken, "Ridge-based vessel segmentation in color images of the retina", IEEE Trans. Med. Imag., vol. 23, no. 4, pp. 501-509, 2004.
22. João V. B. Soares, Jorge J. G. Leandro, Roberto M. Cesar Jr., Herbert F. Jelinek, and Michael J. Cree. "Retinal Vessel Segmentation Using the 2-D Gabor Wavelet and Supervised Classification", IEEE Transactions on Medical Imaging, Vol. 25, No. 9, pp. 1214-1222, 2006.

23. E. Ricci and R. Perfetti, "Retinal Blood Vessel Segmentation Using Line Operators and Support Vector Classification", IEEE Transactions on Medical Imaging, Vol. 26, No. 10, pp. 1357-1365, 2007.

24. Marin, D.; Aquino, A.; Gegundez-Arias, M.E.; Bravo, J.M., "A New Supervised Method for Blood Vessel Segmentation in Retinal Images by Using Gray-Level and Moment Invariants-Based Features", IEEE Transactions on Medical Imaging, Volume: 30, Issue: 1, pp. 146-158, 2011.

25. X. Jiang and D. Mojon, "Adaptive local thresholding by verification-based multithreshold probing with application to vessel detection in retinal images", IEEE Trans. Pattern Anal. Mach. Intell., vol. 25, no. 1, pp. 131-137, 2003.

26. www.fenokulu.net

27. http://www.turkcebilgi.com/g\%C3\%B6z

28. www.atesveates.com/pdf/diyabetikretinopati

29. http://gozdr.com/?p=114

30. Maitra, I.K., Nag, S., Bandyopadhyay, S.K., (2012), "A Novel Edge Detection Algorithm for Digital Mammogram", International Journal of Information and Communication Technology Research, Vol. 2, No. 2, pp. 207-215, ISSN 22234985.

31. Muthukrishnan, R., Radha, M, (2011), "Edge Detection Techniques for Image Segmentation", International Journal of Computer Science \& Information Technology (IJCSIT), Vol. 3, No. 6, pp. $259-267$.

32. Karasulu B., " Automatıc Extraction Of Retinal Blood Vessels: A Software Implementation", Assist. Prof. Dr. at Department of Computer Engineering, Faculty of Engineering, Canakkale Onsekiz Mart University, Canakkale, Turkey

33. Gao, P., Sun, X., Wang, W., (2010), "Moving Object Detection Based on Kirsch Operator Combined with Optical Flow", International Conference on Image Analysis and Signal Processing (IASP), 9-11 April 2010, pp. 620-624. http://www.answers.com/topic/matched-filter

34. Buğday A., "Gerçek Zamanlı Videolarda Ön Plan Arka Plan Ayrımı", Yüksek Lisans Tezi, 93-94, Ankara 2010. 